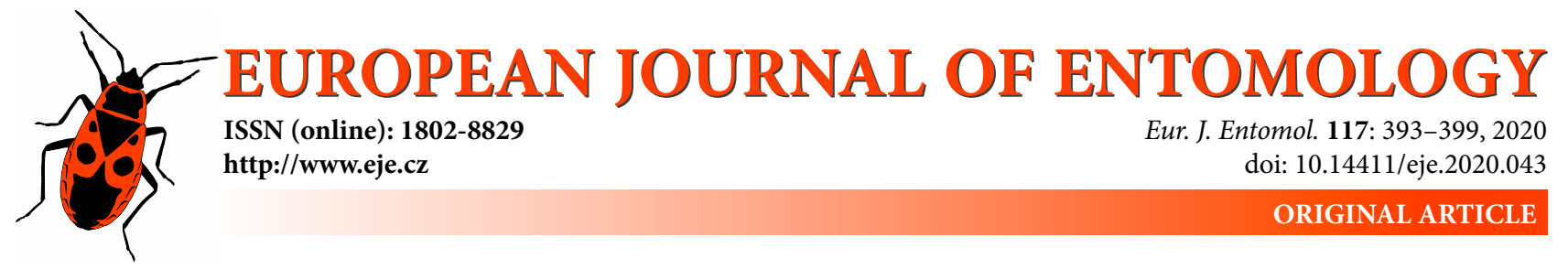

\title{
Effect of supplementary nutrition on the reproduction and mating behaviour of Habrobracon hebetor (Hymenoptera: Braconidae)
}

\author{
YANZhANg HUANG*, AnqI DAI**, Zhenkun MAO, Zhihao CAI and JUnQI JIANG \\ School of Plant Protection, Anhui Agricultural University, 130 Changjiangxilu, Hefei, Anhui, P.R. China; \\ e-mails: huangyz@ahau.edu.cn, 1289968791@qq.com,m1061954683@163.com, onprint@163.com, junqijiang@163.com
}

\begin{abstract}
Key words. Hymenoptera, Braconidae, Habrobracon hebetor, parasitoid, supplementary nutrition, reproductive efficiency, mating ability, Plodia interpunctella, natural enemy

Abstract. To improve the mass production of the parasitoid Habrobracon hebetor (Say) (Hymenoptera: Braconidae) the effects of supplementary nutrition on its reproduction and mating behaviour were investigated using Plodia interpunctella Hübner (Lepidoptera: Pyralidae) larva as a host. The survival of mated male wasps was markedly prolonged after feeding with five different types of nutrients and that of unmated males was markedly prolonged except when provided with yeast solution. Providing female wasps with supplementary nutrition did not affect their longevity. When $H$. hebetor reproduced sexually and was supplied with an abundance of hosts, females produced 101.0 and 96.7 female offspring, respectively, when fed $20 \%$ sucrose or $20 \%$ honey solutions, however, when provided with only ten hosts the provision of supplementary nutrition did not affect the number of female offspring they produced. The $20 \%$ maltose, $20 \%$ sucrose and $20 \%$ honey solutions significantly promoted the courtship behaviour of male wasps, and the $20 \%$ yeast and $20 \%$ honey solutions increased the mating success of males paired with virgin females.
\end{abstract}

\section{INTRODUCTION}

Controlling pests using their natural enemies is one of the most important measures proposed for the development of sustainable agriculture (Ahmad \& Jam, 2015). The control of pests by natural enemies is in accord with the natural order and processes, includes the protection and utilization of indigenous natural enemies in nature and the release of artificially produced natural enemies (Yang et al., 2006). For improving pest control using natural enemies the most immediate and effective means is to simultaneously release artificially produced natural enemies into nature (Michaud, 2018). However, because of the technology needed, unstable effect and high cost it is not a popular method of pest control (Zhang \& Chen, 2014). Therefore, approaches for effectively enhancing the efficiency of artificial breeding and use of natural enemies have been developed by scientists to overcome the obstacles to the use of natural enemy control.

As an ectoparasitoid of the larvae of many kinds of Lepidoptera, $H$. hebetor exerts good control on these insect pests in the field (Benson, 1974; Nay \& Perring, 2005). There is information on the population growth and host location by H. hebetor (Nikam \& Pawar, 1993; Mironidis \& Savopoulou-Soultani, 2009; Adarkwah et al., 2010; Mbata et al., 2017). Previous research show that host species, host density and environmental conditions affect the efficiency of parasitism and reproduction of $H$. hebetor (Magro \& Parra, 2001; Eliopoulos \& Stathas, 2008; Akinkurolere et al., 2009; Faal \& Shishehbor, 2013; Alam et al., 2015). Furthermore, the mating experience of $H$. hebetor influences the sex of their offspring as a higher female-to-male ratio is reported when a male with little mating experience mates with a virgin female (Gündüz \& Gülel, 2005). $H$. hebetor can also adapt its reproductive strategy by producing more offspring and a higher female-to-male ratio when it parasitizes well developed host larvae (Akinkurolere et al., 2009; Al-Taweel et al., 2014; Jarrahi \& Safavi, 2016; Majeed et al., 2018).

The conservation and augmentation of indigenous natural enemies plays a significant role in integrated pest management (IPM). In this respect, supplementary nutrition before parasitism can significantly enhance the pest control effect of Sclerodermus pupariae Yang et Yao (Hymenoptera: Bethylidae) and prolong its longevity. The enhancement effect of honey on the reproduction and longevity of $S$. pupariae adults is similar to that of feeding on host haemolymph (Gao et al., 2016), and H. hebetor fed a 30\% honey solution and supplied daily with one mature instar

\footnotetext{
* Corresponding author; e-mail: huangyz@ahau.edu.cn

** The first two authors contributed equally to the present study.
} 
larva of Corcyra cephalonica Stainton (Lepidotera: Pyralidae) produced most progeny (Kabore et al., 2019). Feeding on honeydew can facilitate host finding by insect natural enemies (Hudak et al., 2003; Araj et al., 2011). The effect of supplementary nutrition on the biological behavior of adults of $H$. hebetor is reported (Mironidis \& SavopoulouSoultani, 2009; Majeed et al., 2018), but not its effect on longevity and mating behaviour. In the present paper, we report the effect of providing supplementary nutrition in the form of one of five nutrient solutions on the reproduction and mating behaviour of adult $H$. hebetor. Our findings will help in improving the mass propagation of this parasitoid and its use as a biocontrol agent.

\section{MATERIALS AND METHODS}

\section{Insects}

Habrobracon hebetor (Say) and Plodia interpunctella were obtained from stock cultures kept in the Laboratory of Insect Physiology and Ecology, School of Plant Protection, Anhui Agricultural University (Hefei, China). P. interpunctella was reared indoors on crushed soybean for many generations and healthy $5^{\text {th }}$ instar larvae of the same size were used in this study. H. hebetor was reared on larvae of $P$. interpunctella for many generations. This was done by placing twenty 5 th-instar larvae of $P$. interpunctella in a $50 \mathrm{~mL}$ plastic tube and then adding four to six pairs of 2 to 7 day old adult wasps after which the opening was sealed with white cotton wool.

The tube containing the wasps and hosts was put in a climate cabinet kept at $26-28^{\circ} \mathrm{C}, 70-80 \%$ relative humidity and a photoperiod of $12 \mathrm{~L}: 12 \mathrm{D}$. After the next generation of parasites pupated, the pupae were each gently introduced into a $10-\mathrm{mL}$ tube, one pupa per tube. Five holes of an approximate diameter of 0.5 $\mathrm{mm}$ were made in the lid of each tube for ventilation. Twenty four hours after the adults emerged healthy and vigorous adult wasps of similar size were used in this study.

\section{Nutrient solutions}

All five nutrient solutions (specifically, honey, sucrose, maltobiose, glucose, and yeast) were respectively prepared as a $20 \%$ solution in water. In addition, one group of controls was fed distilled water and another nothing.

\section{Effect of supplementary nutrition on the longevity of adult $\boldsymbol{H}$. hebetor}

First, a $1.5 \mathrm{~cm} \times 7 \mathrm{~cm}$ piece of clean filter paper was placed in a $10-\mathrm{mL}$ plastic tube and then $180 \mu \mathrm{L}$ of nutrition solution added to the filter paper. Second, two unmated adult wasps less than 1 day old were introduced into each tube. The two wasps in a tube consisted of either two unmated females, or two unmated males or one unmated female and one unmated male. The tube with the pair of adult wasps was not included in the experiment if they did not mate within ten minutes. If the male wasp mounted the female and inserted its phallus for more than one second the mating was regarded as successful. The ten tubes containing either two unmated females or two unmated males were each treated as a group and the twenty tubes containing one unmated female and one unmated male were treated as a group, and each group was replicated six times. The tubes containing adult wasps were placed in a climate chamber kept at $26-28^{\circ} \mathrm{C}, 70-80 \%$ relative humidity and a photoperiod of $12 \mathrm{~L}: 12 \mathrm{D}$. Dead wasps were counted every day until all wasps died. Finally, the average longevity of each group was determined.

\section{Effect of supplementary nutrition on the reproduction of $\boldsymbol{H}$. hebetor}

The supplementary nutrition used was identical to that described in the sub-sections above. Less than 1 day old unmated adult wasps were placed singly in a tube containing a small amount of nutrient solution and after $24 \mathrm{~h}$ the wasp was taken out of the tube and used to determine the effect of this treatment on its reproduction at $26-28^{\circ} \mathrm{C}, 70-80 \%$ relative humidity and a photoperiod of $12 \mathrm{~L}: 12 \mathrm{D}$. This was done by providing these wasps each with ten 5 th-instar larvae of $P$. interpunctella in a 50-mL plastic tube. For sexual reproduction two pairs of unmated wasps were placed in a tube and if mating did not occur in ten minutes, these wasps were not included in the experiment. None of the wasps failed to mate and only one pair failed to copulate successfully. Only two unmated female wasps were placed in a tube for determining the effect on parthenogenetic reproduction. These females were provided with ten unparasitized healthy larvae every two days up to the day the females died. This experiment was replicated six times. The number of eggs laid was recorded daily and the numbers of adult female and male wasps that emerged were recorded. Then, the sex ratio was calculated, but not for those females that reproduced parthenogenetically as they only produced male offspring.

To determine the reproductive performance when wasps were provided with a limited number of hosts, the wasps fed supplementary nutrition were placed in a $50 \mathrm{~mL}$ plastic tube containing ten larvae of $P$. interpunctella. Two pairs of unmated wasps were placed in these tubes and if they did not mate successfully within ten minutes they were not included in the experiment. All of the pairs selected mated successfully within $10 \mathrm{~min}$. For parthenogenetic reproduction two unmated female wasps were placed in a tube. In order to reduce the error associated with insect ageing the period allowed for mating was short. This experiment was replicated six times. The number of eggs was recorded daily and then summed, the numbers of female and male adult progeny was recorded and the sex ratio calculated, but not in the case of parthenogenetic reproduction when only male offspring were produced.

\section{Effect of supplementary nutrition on the mating behaviour of $\boldsymbol{H}$. hebetor}

To determine the effect of supplementary nutrition on the mating behaviour of males paired with virgin females a 1-2 day old unmated male wasp was placed in a $10 \mathrm{~mL}$ transparent tube and then a same aged unmated female wasp. The courtship of the male, the time spent mating and duration of mating were recorded over a period of ten minutes. The courtship frequency of males was measured in terms of the number of times a wasp fanned its wings (Huang et al., 2018), which was divided into four grades (from weak to strong), namely, 0 signified no wing-fanning, 1 signified weak (lasted less than $2 \mathrm{~s}$ ), 2 moderate (lasted $\geq 2$ but $<$ $4 \mathrm{~s}$ ) and 3 strong (lasted $\geq 4 \mathrm{~s}$ ). After observation for $10 \mathrm{~min}$ the female wasp was gently removed and the male wasp left alone in the tube for $20 \mathrm{~min}$. Almost immediately, the male paired again with another virgin female, which was again observed for $10 \mathrm{~min}$, and so on. The maximum number of time a male paired with virgin females was eight. This experiment was replicated six times and the total number of observations was 48 . The environmental conditions during the observations were $24-26^{\circ} \mathrm{C}, 70-80 \%$ relative humidity and away from direct sunlight.

To determine the effect of supplementary nutrition on the mating behaviour of a female paired with a virgin male, one 1-2 day old unmated female was placed in a $10-\mathrm{mL}$ transparent tube and then an unmated male of the same age. The courtship of the male, mating times and duration of mating were recorded using the method described above. Each female was paired with up to 
Table 1. Effect of supplementary nutrition on the longevity of adults of $H$. hebetor $\left(27^{\circ} \mathrm{C} \pm 1^{\circ} \mathrm{C}\right)$.

\begin{tabular}{|c|c|c|c|c|}
\hline \multirow{2}{*}{ Nutrient solution } & \multicolumn{4}{|c|}{ Mean longevity (days) \pm SD } \\
\hline & Mated female & Mated male & Virgin female & Virgin male \\
\hline $20 \%$ honey & $7.68 \pm 0.26$ b CD & $7.93 \pm 0.44$ a A & $8.07 \pm 0.58$ b B & $7.03 \pm 0.47$ a $A B$ \\
\hline $20 \%$ sucrose & $7.95 \pm 0.70 \mathrm{~b} \mathrm{BC}$ & $7.53 \pm 0.35$ bc AB & $9.23 \pm 0.33$ a A & $7.34 \pm 0.39$ a A \\
\hline $20 \%$ maltose & $8.79 \pm 0.39$ a $A$ & $7.72 \pm 0.33 \mathrm{ab} A$ & $7.28 \pm 0.48$ c C & $6.58 \pm 0.38 \mathrm{~b} \mathrm{BC}$ \\
\hline $20 \%$ glucose & $7.17 \pm 0.35 c \mathrm{D}$ & $6.83 \pm 0.25 \mathrm{~d} \mathrm{C}$ & $8.27 \pm 0.43 b B$ & $6.48 \pm 0.44$ b BCD \\
\hline $20 \%$ yeast & $8.57 \pm 0.17$ a $A B$ & $7.20 \pm 0.13 \mathrm{~cd} \mathrm{BC}$ & $8.49 \pm 0.27 b$ B & $6.02 \pm 0.25$ c CDE \\
\hline Water & $7.98 \pm 0.22 \mathrm{~b} \mathrm{BC}$ & $7.08 \pm 0.23 \mathrm{~d} \mathrm{BC}$ & $6.90 \pm 0.44$ c C & $5.63 \pm 0.40$ с E \\
\hline Control & $8.47 \pm 0.27$ a $A B$ & $4.52 \pm 0.25$ e D & $9.37 \pm 0.25$ a A & $5.85 \pm 0.29 \mathrm{c} \mathrm{DE}$ \\
\hline
\end{tabular}

Note: Values of $F, d f$ and $P$ are listed as follows: (1) Mated female: $F=13.594 ; \mathrm{df}=6,41 ; \mathrm{P}<0.0001 ;(2) \mathrm{Mated}$ male: $\mathrm{F}=88.539 ; \mathrm{df}=6$, 41; $P<0.0001$; (3) Virgin female: $F=30.015 ; d f=6,41 ; P<0.0001 ;(4)$ Virgin male: $F=16.236 ; d f=6,41 ; P<0.0001$.

four virgin males. In order to reduce the error due insect age, the observations were carried out over a period of $12 \mathrm{~h}$ and replicated six times giving a total number of observations of 24 . The experimental conditions were also the same as mentioned above.

\section{Statistical analysis}

Data were analysed using the analysis of variance in the DPS 2000 program (Tang \& Feng, 2002). Means were compared and separated using Duncan's new multiple range method at significance levels of 0.05 and 0.01 , respectively. Means $( \pm \mathrm{SD})$ in the same column followed by different lower case and capital letters were significantly different at the $\mathrm{P}=0.05$ and 0.01 levels, respectively. Means $( \pm \mathrm{SD})$ of untransformed data are presented.

\section{RESULTS}

\section{Effect of supplementary nutrition on the longevity of adult $\boldsymbol{H}$. hebetor}

After feeding with different supplementary nutrients, the number of dead adult wasps was counted and recorded daily and used to determine mean longevity. As recorded in Table 1, there was no obvious effect of the different supplementary nutrients in prolonging the longevity of virgin female $H$. hebetor, in fact, their life expectancy was lower than that of the control except for the $20 \%$ sucrose solution. Mean longevities of mated females fed additional nutrients were significantly lower than those of the control, except for those provided with 20\% maltose and $20 \%$ yeast solutions. In summary, the supplementary nutrition did not prolong the longevity of female wasps.

Supplementary nutrition, however, prolonged male longevity. The longevities of mated males provided with nutrients and water were significantly longer than that of the control and that of unmated males were significantly longer than that of the control, except for the $20 \%$ solution of yeast. Overall, males provided with supplementary nutrition lived for longer, especially the mated males. Of the nutrient solutions provided, $20 \%$ honey, $20 \%$ maltose and $20 \%$ sucrose very significantly prolonged the mean longevities of both mated and unmated males $(\mathrm{P}<0.01)$.

\section{Effect of supplementary nutrition on the reproductive performance of $\boldsymbol{H}$. hebetor}

\section{Supplied with an abundance of hosts}

After feeding with different supplementary nutrients, the number of ovipositions was recorded daily (Table 2). The number of ovipositions recorded for mated wasps provided with the five nutrient solutions and water was more than that for the control, with a very significant effects recorded for $20 \%$ maltose and $20 \%$ sucrose $(\mathrm{P}<0.01)$. Of the five nutrients, the $20 \%$ sucrose resulted in the best production of female and female plus male offspring of 101.0 and

Table 2. Effect of supplementary nutrition on fecundity of adults of $H$. hebetor supplied with an abundance of hosts $\left(27^{\circ} \mathrm{C} \pm 1^{\circ} \mathrm{C}\right)$.

\begin{tabular}{|c|c|c|c|c|c|c|c|}
\hline \multirow[b]{2}{*}{ Treatment } & \multicolumn{5}{|c|}{ Sexual reproduction } & \multicolumn{2}{|c|}{ Parthenogenesis } \\
\hline & $\begin{array}{c}\text { Oviposition } \\
\text { number } \pm \text { SD }\end{array}$ & $\begin{array}{c}\text { Female } \\
\text { number } \pm S D\end{array}$ & $\begin{array}{c}\text { Male } \\
\text { number } \pm \text { SD }\end{array}$ & $\begin{array}{l}\text { Total number } \\
\text { of adults } \pm \text { SD }\end{array}$ & Sex ratio $\pm S D$ & $\begin{array}{c}\text { Oviposition } \\
\text { number } \pm \text { SD }\end{array}$ & $\begin{array}{c}\text { Male } \\
\text { number } \pm \text { SD }\end{array}$ \\
\hline $20 \%$ honey & $\begin{array}{c}613.0 \pm 131.8 \\
a A B\end{array}$ & $\begin{array}{c}96.7 \pm 43.5 \\
\text { a A }\end{array}$ & $\begin{array}{c}126.5 \pm 45.4 \\
\text { a A }\end{array}$ & $\begin{array}{c}223.2 \pm 45.2 \\
\text { a A }\end{array}$ & $\begin{array}{c}0.87 \pm 0.43 \\
\text { a A }\end{array}$ & $\begin{array}{c}546.2 \pm 125.6 \\
\text { a A }\end{array}$ & $\begin{array}{c}245.2 \pm 60.1 \\
\text { a A }\end{array}$ \\
\hline $20 \%$ sucrose & $\begin{array}{c}631.5 \pm 97.1 \\
\text { a A }\end{array}$ & $\begin{array}{c}101.0 \pm 15.4 \\
\text { a A }\end{array}$ & $\begin{array}{c}127.7 \pm 39.5 \\
\text { a A }\end{array}$ & $\begin{array}{c}230.3 \pm 40.4 \\
\text { a A }\end{array}$ & $\begin{array}{c}0.84 \pm 0.21 \\
\text { a A }\end{array}$ & $\begin{array}{c}583.0 \pm 91.4 \\
\text { a A }\end{array}$ & $\begin{array}{c}246.3 \pm 33.3 \\
\text { a A }\end{array}$ \\
\hline $20 \%$ maltose & $\begin{array}{c}643.5 \pm 83.5 \\
\text { a A }\end{array}$ & $\begin{array}{c}95.3 \pm 40.6 \\
\text { a A }\end{array}$ & $\begin{array}{c}116.3 \pm 39.8 \\
\text { a A }\end{array}$ & $\begin{array}{c}211.7 \pm 53.3 \\
\text { ab A }\end{array}$ & $\begin{array}{c}0.88 \pm 0.37 \\
\text { a A }\end{array}$ & $\begin{array}{c}485.5 \pm 162.4 \\
\text { a A }\end{array}$ & $\begin{array}{c}214.2 \pm 55.0 \\
\text { a A }\end{array}$ \\
\hline $20 \%$ glucose & $\begin{array}{c}614.8 \pm 84.6 \\
\text { a AB }\end{array}$ & $\begin{array}{c}73.2 \pm 8.1 \\
\text { a A }\end{array}$ & $\begin{array}{c}130.3 \pm 50.2 \\
\text { a A }\end{array}$ & $\begin{array}{c}203.5 \pm 51.0 \\
\text { ab A }\end{array}$ & $\begin{array}{c}0.65 \pm 0.28 \\
\text { a A }\end{array}$ & $\begin{array}{c}630.0 \pm 127.8 \\
\text { a A }\end{array}$ & $\begin{array}{c}254.0 \pm 63.0 \\
\text { a A }\end{array}$ \\
\hline $20 \%$ yeast & $\begin{array}{c}591.5 \pm 79.9 \\
\text { a AB }\end{array}$ & $\begin{array}{c}80.5 \pm 33.7 \\
\text { a A }\end{array}$ & $\begin{array}{c}99.5 \pm 30.5 \\
\text { a A }\end{array}$ & $\begin{array}{c}180.0 \pm 44.8 \\
a b A\end{array}$ & $\begin{array}{c}0.89 \pm 0.42 \\
\text { a A }\end{array}$ & $\begin{array}{c}577.5 \pm 89.3 \\
\text { a A }\end{array}$ & $\begin{array}{c}251.8 \pm 43.8 \\
\text { a A }\end{array}$ \\
\hline Water & $\begin{array}{c}575.5 \pm 67.1 \\
\text { a AB }\end{array}$ & $\begin{array}{c}95.7 \pm 21.2 \\
\text { a A }\end{array}$ & $\begin{array}{c}97.3 \pm 23.9 \\
\text { a A }\end{array}$ & $\begin{array}{c}193.0 \pm 44.2 \\
\text { ab A }\end{array}$ & $\begin{array}{c}0.99 \pm 0.11 \\
\text { a A }\end{array}$ & $\begin{array}{c}538.0 \pm 127.4 \\
\text { a A }\end{array}$ & $\begin{array}{c}217.7 \pm 59.7 \\
\text { a A }\end{array}$ \\
\hline Control & $\begin{array}{c}448.0 \pm 129.0 \\
\text { b B }\end{array}$ & $\begin{array}{c}71.8 \pm 19.8 \\
\text { a A }\end{array}$ & $\begin{array}{c}89.5 \pm 34.3 \\
\text { a A }\end{array}$ & $\begin{array}{c}161.3 \pm 44.3 \\
\text { b A }\end{array}$ & $\begin{array}{c}0.90 \pm 0.35 \\
\text { a A }\end{array}$ & $\begin{array}{c}588.8 \pm 137.5 \\
\text { a A }\end{array}$ & $\begin{array}{c}252.5 \pm 81.9 \\
\text { a A }\end{array}$ \\
\hline
\end{tabular}

Note: Values of $F, d f$ and $P$ are listed as follows: (1) Sexual reproduction: Oviposition number, $F=2.668$; df = 6, 41; $P=0.0308$; Female number, $F=1.075 ; \mathrm{df}=6,41 ; \mathrm{P}=0.3960 ;$ Male number, $\mathrm{F}=1.134 ; \mathrm{df}=6,41 ; \mathrm{P}=0.3636 ;$ Total number of adult, $\mathrm{F}=1.652 ; \mathrm{df}=6,41 ; \mathrm{P}$ $=0.1622 ;$ Sex ratio, $F=0.5890 ; \mathrm{df}=6,41 ; \mathrm{P}=0.7371 ;(2)$ Parthenogenesis: Oviposition number, $F=0.805 ; \mathrm{df}=6,41 ; \mathrm{P}=0.5729 ; \mathrm{Male}$ number, $F=0.505 ; \mathrm{df}=6,41 ; \mathrm{P}=0.8005$. 
Table 3. Effect of supplementary nutrition on fecundity of $H$. hebetor adults supplied with only ten hosts $\left(27^{\circ} \mathrm{C} \pm 1^{\circ} \mathrm{C}\right)$.

\begin{tabular}{|c|c|c|c|c|c|}
\hline \multirow{2}{*}{ Treatment } & \multicolumn{4}{|c|}{ Sexual reproduction } & \multirow{2}{*}{$\begin{array}{l}\text { Parthenogenesis } \\
\text { Male number } \pm \text { SD }\end{array}$} \\
\hline & Female number \pm SD & Male number \pm SD & Total number of adults \pm SD & Sex ratio $\pm S D$ & \\
\hline $20 \%$ honey & $21.7 \pm 3.1$ a A & $15.5 \pm 3.7 \mathrm{abc} A B$ & $37.2 \pm 6.0 \mathrm{ab} A$ & $1.5 \pm 0.3 \mathrm{ab} A$ & $43.0 \pm 13.8$ a A \\
\hline $20 \%$ sucrose & $18.7 \pm 6.1$ a $A$ & $20.2 \pm 7.2$ a $A$ & $38.8 \pm 4.1$ a $A$ & $1.1 \pm 0.6 \mathrm{~b} \mathrm{~A}$ & $39.0 \pm 8.6$ a A \\
\hline $20 \%$ maltose & $17.3 \pm 9.4$ a $A$ & $15.3 \pm 5.2 \mathrm{abc} A B$ & $32.7 \pm 7.5 \mathrm{ab} A$ & $1.2 \pm 0.7 \mathrm{ab} A$ & $42.7 \pm 12.4$ a A \\
\hline $20 \%$ glucose & $16.5 \pm 7.5$ a $A$ & $14.3 \pm 1.8 \mathrm{abc} A B$ & $30.8 \pm 8.4$ ab A & $1.2 \pm 0.5 \mathrm{~b} \mathrm{~A}$ & $39.2 \pm 11.5$ a $A$ \\
\hline $20 \%$ yeast & $21.7 \pm 4.3$ a $A$ & $17.7 \pm 4.9 \mathrm{ab} \mathrm{AB}$ & $39.3 \pm 8.0$ a $A$ & $1.3 \pm 0.3 a b A$ & $41.2 \pm 11.4$ a $A$ \\
\hline Water & $17.8 \pm 3.4$ a $A$ & $12.8 \pm 6.4 \mathrm{bc} A B$ & $30.7 \pm 7.0 \mathrm{ab} A$ & $1.7 \pm 0.8 \mathrm{ab} A$ & $38.8 \pm 10.1$ a A \\
\hline Control & $18.8 \pm 3.8$ a $A$ & $10.3 \pm 3.1$ c B & $29.2 \pm 6.4$ b A & $1.9 \pm 0.5$ a A & $40.5 \pm 11.5$ a $A$ \\
\hline
\end{tabular}

Note: Values of $F, d f$ and $P$ are listed as follows: (1) Sexual reproduction: Female number, $F=0.729 ; d f=6,41 ; P=0.6293$; Male number, $F=2.512 ; d f=6,41 ; P=0.0398 ;$ Total number of adults, $F=2.271 ; d f=6,41 ; P=0.0590 ;$ Sex ratio, $F=1.713 ; d f=6,41 ; P=0.1470 ;$ (2) Parthenogenesis: Male number, $F=0.138 ; d f=6,41 ; P=0.9902$.

230.3 , respectively, followed by $20 \%$ honey with 96.7 and 223.2, respectively. Furthermore, none of the five nutrient solutions significantly affected the production of offspring by unmated wasps.

\section{Supplied with ten host larvae}

In this experiment, the parent wasp was initially fed one of the supplementary nutrients for $24 \mathrm{~h}$ and then provided with hosts for parasitism. The number of offspring was determined at emergence (Table 3). The number of females and the sex ratio of the offspring of unmated wasps were not significantly affected by providing them with any of the five nutrient solutions. Number of male and total number of offspring produced by mated wasps provided with $20 \%$ yeast and $20 \%$ sucrose solutions were significantly more than that of the control. Overall, the mated wasps provided with $20 \%$ honey and $20 \%$ yeast solutions produced more females and total progeny. Furthermore, the unmated females provided with the nutrient solutions did not produce significantly more male progeny than the control. Nevertheless, those provided with $20 \%$ honey, $20 \%$ maltose and $20 \%$ yeast solutions produced relatively more progeny.

\section{Effect of supplementary nutrition on the mating behaviour of $\boldsymbol{H}$. hebetor}

The effect of supplementary nutrition on the mating behaviour of $H$. hebetor is presented in Table 4 . The courtship intensity of males with unmated females did not differ significantly from that recorded for the control. A higher courtship frequency and stronger desire for mating, however, were recorded for males provided with $20 \%$ sucrose, $20 \%$ honey and 20\% maltose solutions. Moreover, the sexual activity of those provided with $20 \%$ yeast and $20 \%$ honey solutions was markedly higher. The average mating frequencies of the males provided with these two nutrient solutions were more than nine times and the duration of mating was $162.0 \mathrm{~s}$ and $155.8 \mathrm{~s}$ respectively. The average durations of mating recorded for $H$. hebetor provided with nutrient solutions did not differ significantly from that recorded for the control.

When wasps previously provided with $20 \%$ maltose, $20 \%$ honey and $20 \%$ sucrose solutions, were mated with unmated males the courtship behaviour of the males was significantly more marked than that of wasps provided with the other nutrient solutions and the control, as the courtship frequencies were $69.8,67.8$ and 66.2, respectively (Table 5). There was no significant increase in mating by the wasps provided with these nutrient solutions compared with the control. The duration of mating of males previously provided with $20 \%$ glucose solution was the longest, whereas that of those provided with $20 \%$ sucrose and $20 \%$ yeast solutions were shorter than that of the control.

\section{DISCUSSION}

This research indicates ways in which the mass production of $H$. hebetor can be improved. Providing males with sucrose, honey, maltose or glucose solutions prolongs the length of time for which they survive, but not the females. When this wasp is kept indoors, it is difficult to keep the female and male wasps separately and most of the wasps successfully mated in the mixed female and male cultures, so we recommend providing the wasps with either a $20 \%$ maltose or $20 \%$ yeast solution. Recently, it was reported

Table 4. Effect of supplementary nutrition on mating behaviour of males of $H$. hebetor mated with virgin females $\left(25^{\circ} \mathrm{C} \pm 1^{\circ} \mathrm{C}\right)$.

\begin{tabular}{|c|c|c|c|c|c|}
\hline Treatment & $\begin{array}{c}\text { Courtship } \\
\text { frequency } \pm S D\end{array}$ & $\begin{array}{c}\text { Courtship } \\
\text { intensity } \pm \text { SD }\end{array}$ & $\begin{array}{c}\text { Mating } \\
\text { frequency } \pm S D\end{array}$ & $\begin{array}{l}\text { Total time spent } \\
\text { mating }(\mathrm{s}) \pm S D\end{array}$ & $\begin{array}{l}\text { Average duration } \\
\text { of a mating (s) } \pm S D\end{array}$ \\
\hline $20 \%$ honey & $91.2 \pm 20.1 \mathrm{ab} A B$ & $1.72 \pm 0.3 a \mathrm{~A}$ & $9.16 \pm 2.9 \mathrm{ab} A$ & $155.8 \pm 55.1$ a $A$ & $16.9 \pm 2.3 a A$ \\
\hline $20 \%$ sucrose & $114.3 \pm 45.7$ a A & $1.65 \pm 0.5$ a A & $6.83 \pm 2.2 \mathrm{ab} A$ & $127.7 \pm 39.8 \mathrm{ab} A$ & $19.4 \pm 6.4 \mathrm{a} \mathrm{A}$ \\
\hline $20 \%$ maltose & $90.3 \pm 39.7 \mathrm{ab} A B$ & $1.43 \pm 0.4$ a A & $7.83 \pm 2.4 \mathrm{ab} \mathrm{A}$ & $152.2 \pm 54.8$ a A & $19.4 \pm 3.2 \mathrm{a} \mathrm{A}$ \\
\hline $20 \%$ glucose & $72.2 \pm 29.6 \mathrm{ab} A B$ & $1.36 \pm 0.4$ a A & $7.67 \pm 3.1 \mathrm{ab} A$ & $148.2 \pm 47.2$ a A & $21.2 \pm 7.8$ a $A$ \\
\hline $20 \%$ yeast & $84.3 \pm 34.1 \mathrm{ab} A B$ & $1.56 \pm 0.4$ a A & $9.67 \pm 1.9$ a A & $162.0 \pm 33.8$ a A & $16.9 \pm 2.7$ a A \\
\hline Water & $49.2 \pm 26.6$ b B & $1.20 \pm 0.5$ a A & $5.83 \pm 3.1 \mathrm{~b} \mathrm{~A}$ & $85.3 \pm 37.5$ b A & $16.5 \pm 6.7$ a $A$ \\
\hline Control & $76.5 \pm 30.4 \mathrm{ab} A B$ & $1.42 \pm 0.5 \mathrm{a} \mathrm{A}$ & $8.83 \pm 3.4 \mathrm{ab} \mathrm{A}$ & $138.8 \pm 32.9 \mathrm{ab} A$ & $16.7 \pm 4.1 \mathrm{a} \mathrm{A}$ \\
\hline
\end{tabular}

Note: Values of $F$, df and $P$ are listed as follows: (1) Courtship frequency: $F=2.176$; $d f=6,41 ; P=0.0689 ;$ (2) Courtship intensity: $F=$ 1.005; $d f=6,41 ; P=0.4378 ;(3)$ Mating frequency: $F=1.446 ; d f=6,41 ; P=0.2254 ;(4)$ Mating duration: $F=2.116 ; d f=6,41 ; P=0.0761$; (5) Mating duration every time: $F=0.767 ; \mathrm{df}=6,41 ; P=0.6009$. 
Table 5. Effect of supplementary nutrition on mating behaviour of males of $H$. hebetor mated with virgin females $\left(25^{\circ} \mathrm{C} \pm 1^{\circ} \mathrm{C}\right)$.

\begin{tabular}{|c|c|c|c|c|c|}
\hline Treatment & $\begin{array}{c}\text { Courtship } \\
\text { frequency } \pm \text { SD }\end{array}$ & $\begin{array}{c}\text { Courtship } \\
\text { intensity } \pm S D\end{array}$ & Mating frequency $\pm S D$ & $\begin{array}{l}\text { Total time spent } \\
\text { mating (s) } \pm S D\end{array}$ & $\begin{array}{l}\text { Average duration } \\
\text { of mating }(\mathrm{s}) \pm S D\end{array}$ \\
\hline $20 \%$ of honey & $66.2 \pm 25.2$ a $A$ & $1.28 \pm 0.3 \mathrm{ab} A B$ & $1.33 \pm 0.5$ a A & $21.0 \pm 10.1$ a $A$ & $16.2 \pm 5.3$ a $A$ \\
\hline $20 \%$ of sucrose & $67.8 \pm 24.7$ a A & $1.73 \pm 0.5$ a A & $1.17 \pm 0.4 \mathrm{a} \mathrm{A}$ & $18.0 \pm 7.0$ a A & $15.3 \pm 1.4$ a $A$ \\
\hline $20 \%$ of maltose & $69.8 \pm 21.9$ a $A$ & $1.18 \pm 0.6 \mathrm{ab} A B$ & $1.17 \pm 0.4$ a A & $26.5 \pm 18.4 \mathrm{a} \mathrm{A}$ & $23.7 \pm 12.7$ a A \\
\hline $20 \%$ of glucose & $28.2 \pm 23.7 \mathrm{~b} \mathrm{~B}$ & $1.18 \pm 0.6 \mathrm{ab} A B$ & $1.67 \pm 0.5$ a A & $28.0 \pm 9.6$ a A & $17.2 \pm 3.1$ a A \\
\hline $20 \%$ of yeast & $33.3 \pm 14.1 \mathrm{~b} \mathrm{~B}$ & $0.90 \pm 0.3 b \mathrm{AB}$ & $1.17 \pm 0.4 \mathrm{a} \mathrm{A}$ & $18.5 \pm 5.9$ a $A$ & $16.0 \pm 1.7$ a $A$ \\
\hline Clear water & $22.2 \pm 13.1 \mathrm{~b} \mathrm{~B}$ & $0.82 \pm 0.8$ b B & $1.33 \pm 0.5$ a A & $24.8 \pm 14.3$ a A & $18.5 \pm 5.6$ a $A$ \\
\hline Control & $32.8 \pm 6.4$ b B & $1.20 \pm 0.3 \mathrm{ab} A B$ & $1.33 \pm 0.5$ a A & $21.0 \pm 7.4$ a A & $16.8 \pm 7.5$ a $A$ \\
\hline
\end{tabular}

Note: Values of $F, d f$ and $P$ are listed as follows: (1)Courtship frequency: $F=6.933 ; d f=6,41 ; P=0.0001 ;(2)$ Courtship intensity: $F=$ 2.068; $d f=6,41 ; P=0.0823 ;(3)$ Mating frequency: $F=0.851 ; d f=6,41 ; P=0.5399 ;(4)$ Total time spent mating: $F=0.740 ; d f=6,41 ; P$ $=0.6208 ;(5)$ Average duration of mating: $F=1.159 ; \mathrm{df}=6,41 ; \mathrm{P}=0.3501$.

that $H$. hebetor can be mass produced using the larvae of $C$. cephalonica and Galleria mellonela L. (Lepidotera: Pyralidae) as hosts (Magro \& Parra, 2001; Chen et al., 2012; Kryukov et al., 2013), but it is unknown to what extent the production could be increased by providing food for the adults in the form of nutrient solutions. In view of their enormous potential fecundity, the emphasis should be put on effectively providing a nutrient resource for the adult wasps and improving the survival of the larvae of $H$. hebetor. Because a supplementary nutrient based on yeast, effectively increases the number of offspring produced, this is the most appropriate nutrient to provide when the supply of hosts is limited. We recommend $20 \%$ sucrose or $20 \%$ honey solutions when the parasitic wasp is provided with an abundance of hosts, but $20 \%$ yeast or $20 \%$ honey solutions should be provided when the availability of hosts is limited.

At present, $H$. hebetor is used to control some Lepidopteran pests, such as Ostrinia furnacalis Guenée (Lepidoptera: Pyralidae), Helicoverpa armigera (Hübner) (Lepidoptera: Noctuidae), Ephestia elutella (Hübner) (Lepidoptera: Pyralidae) and Ephestia cautella (Walker) (Lepidoptera: Pyralidae), etc. (Chen et al., 2011; Saxena et al., 2012; Ghimire \& Phillips, 2014; Borzoui et al., 2016). As it is difficult to establish a stable population of parasitic wasps in the field or a warehouse by means of a single release of the wasp, they have to be released many times to achieve control. To effectively enhance the control of insects by natural enemies in nature, we recommend that the wasp should be provided with $20 \%$ honey solution before release. The honey solution provides male wasps with a source of energy for finding mates and females with nutrients for developing eggs. Furthermore, honey solution improves mating, increases the number of offspring produced and results in a more favourable sex ratio.

The provision of supplementary nutrients results in an obvious effect on the lifespan and reproduction of many insects (Harvey et al., 2012; Chau et al., 2019) and also markedly enhances the rate of parasitism of many parasitoids (Vaello et al., 2018). The reproductive strategy of males is to locate and mate with as many females as possible (Majeed et al., 2018). Male wasps usually spend more time than the females flying and fanning their wings, so providing a high energy source, such as sucrose, is likely to prolong their life span and so increase their probability of mating.

The reproductive strategy of females of $H$. hebetor is during the larval stage to accumulate the nutrients they need for producing eggs and in the adult stage to search for suitable hosts and lay as many eggs as possible. Therefore, providing them with supplementary nutrients had no noticeable effect on their life span. Most females of $H$. hebetor usually mate only once, with just a few mating twice or three times (Majeed et al., 2018). When the female wasps were paired with unmated males, the provision nutrient supplements significantly promoted the courtship behaviour of the males, but did not significantly affect their mating success.

Furthermore, artificial supplements are reported to alter the lifespan and fecundity of parasitic wasps. Askari Seyahooei et al. (2018) report that providing carbohydrates in the absence of host larvae significantly prolonged the lifespans of both mated and virgin $H$. hebetor. Male and female Cotesia vestalis Haliday (Hymenoptera: Braconidae) that fed on Cosmos sulphureus, Lantana camara and Coriandrum sativum survived significantly longer than those provided with water or Zinnia elegans (Chau et al., 2019). Our results indicate that supplementary nutrition prolongs the lifespan of male wasps, but not female wasps, and the lifespan of unmated females is shorter than that of the control. We don't know why providing some of the solutions resulted in a shortening of female longevity. Similarly, adult Diachasmimorpha longicaudata (Ashmead) (Hymenoptera: Braconidae) can survive as well on diets of orange or peach juice as on honey. In contrast, providing guava juice results in a reduction in longevity (Sivinski et al., 2006; Benelli et al., 2017). Compared with those fed honey, sugar and date syrups, $H$. hebetor females fed 50\% honey solution laid significantly more eggs and produced more progeny (Ashraf et al., 2017). Our results were similar, i.e., $H$. hebetor females fed on honey produced more progeny. Of the following supplements: honey, glucose, galactose and sucrose, female Ooencyrtus nezarae Ishii (Hymenoptera: Encyrtidae) fed on honey were the most fecund (Teraoka \& Numata, 2000).

Effective production of natural enemies is the key to the successful application of insect pest control. Some research indicates that honey solution is more effective than a sucrose solution in prolonging the life span of $H$. 
hebetor (Majeed et al., 2018), and this is more pronounced for females than males. Our results, however, indicate the opposite as providing a nutrient solution resulted in a greater lengthening of the lifespan of male wasps than of female wasps. This difference might be due to the age of the insects, feeding method, nutrient concentration or experimental error, etc. Therefore, to provide optimal conditions for the rearing and reproduction of $H$. hebetor, further research work is needed on the effect of temperature, nutrient composition and feeding frequency on the life span and reproductive behaviour of adult wasps.

ACKNOWLEDGEMENTS. This study was funded by the Key Natural Science Fund of Education Department of Anhui Province, China (KJ2014A076), the Nature Science Research Project of Anhui Province, China (1808085MC83) and the National Key R\&D Program of China Grant/Award (No. 2017YFD0201000).

\section{REFERENCES}

Adarkwah C., Büttner C., Reichmuth C., Obeng-Ofori D., ProZELL S. \& SCHÖLLER M. 2010: Ability of the larval ectoparasitoid Habrobracon hebetor (Say, 1836) (Hymenoptera: Braconidae) to locate the rice moth Corcyra cephalonica (Stainton, 1865) (Lepidoptera: Pyralidae) in bagged and bulk stored rice. - J. Plant Dis. Prot. 117: 67-70.

Ahmad N. \& JAM N.A. 2015: Insect pest management in conservation agriculture. In Farooq M. \& Siddique K. (eds): Conservation Agriculture. Springer, Dordrecht, pp. 133-155.

Akinkurolere R.O., Boyer S., Chen H. \& Zhang H.Y. 2009: Parasitism and host-location preference in Habrobracon hebetor (Hymenoptera: Braconidae): Role of refuge, choice, and host instar. - J. Econ. Entomol. 102: 610-615.

Alam M., Alam S., Miah M., Mian M. \& Hossain M. 2015: Mass rearing of Bracon hebetor (Hym.: Braconidae) on wax moth, Galleria mellonella (Lep.: Pyralidae) with varying density of parasitoid and the host. - J. Crop Prot. 5: 39-48.

Al-Taweel A.A., Mohsen A.A., Hamad B.S. \& Mahmood E.A. 2014: Effect of temperature on the functional response of Bracon hebetor Say (Hymenoptera: Braconidae) to various densities of the host, Ephestia cautella (Walker) larvae. - Am.Euras. J. Sustain. Agric. 8: 71-75.

Araj S.E., Wratten S., Lister A., Buckley H. \& Ghabeish I. 2011: Searching behavior of an aphid parasitoid and its hyperparasitoid with and without floral nectar. - Biol. Contr. 57: $79-84$.

Ashraf S., Abdin Z., Abbas S.K., Khan R.S.A., Tahir M., Rasool S., Anwar M. \& Hussain F. 2017: Effect of different diet concentrations on longevity and fecundity of parasitic wasp Bracon hebetor (Say) (Hymenoptera: Braconidae). - Pak. J. Zool. 49: 761-767.

Askari Seyahooei M., Bagheri A., Bavaghar M., Dousti A.F., \& PARICHeHReH S. 2018: Mating and carbohydrate feeding impacts on life-history traits of Habrobracon hebetor (Hymenoptera: Braconidae). - J. Econ. Entomol. 111: 2605-2610.

Benelli G., Giunti G., Tena A., Desneux N., Caselli A. \& CanaLE A. 2017: The impact of adult diet on parasitoid reproductive performance. - J. Pest Sci. 90: 807-823.

Benson J.F. 1974: Population dynamics of Bracon hebetor Say (Hymenoptera: Braconidae) and Ephestia cautella (Walker) (Lepidoptera: Pyralidae) in a laboratory ecosystem. - J. Anim. Ecol. 43: 71-86.

Borzoui E., Naseri B. \& Mohammadzadeh-Bidarani M. 2016: Adaptation of Habrobracon hebetor (Hymenoptera: Braconi- dae) to rearing on Ephestia kuehniella (Lepidoptera: Pyralidae) and Helicoverpa armigera (Lepidoptera: Noctuidae). - J. Insect Sci. 16: 12, 7 pp.

Chau N.N.B., Kieu N.T.P., Van Tri Dung N., Quoc N.B. \& Phuong T.K. 2019: Effects of floral resources on the longevity and parasitism of Cotesia vestalis Haliday (Hymenoptera: Braconidae) on Plutella xylostella (L.) (Lepidoptera: Plutellidae) in Vietnam. - Heliyon 5: e2258, 5 pp.

Chen H.L., Opit G.P., Sheng P. \& Zhang H.Y. 2011: Maternal and progeny quality of Habrobracon hebetor Say (Hymenoptera: Braconidae) after cold storage. - Biol. Contr. 58: 255-261.

Chen H.L., Zhang H.Y., Zhe K.Y., Zhu K.Y. \& Throne J. 2012: Performance of diapausing parasitoid wasps, Habrobracon hebetor after cold storage. - Biol. Contr. 64: 186-194.

Eliopoulos P.A. \& Stathas G.J. 2008: Life tables of Habrobracon hebetor (Hymenoptera: Braconidae) parasitizing Anagasta kuehniella and Plodia interpunctella (Lepidoptera: Pyralidae): effect of host density. - J. Econ. Entomol. 101: 982-988.

FAAL M.A.H. \& ShISHehBor P. 2013: Biological parameters of Bracon hebetor (Hymenoptera: Braconidae) parasitizing Ephestia kuehniella (Lepidoptera: Pyralidae): Effect of host diet. J. Crop Prot. 2: 411-419.

GaO S.K., Wei K., TANG Y.L., WANG X.Y. \& YANG Z.Q. 2016: Effect of parasitoid density on the timing of parasitism and development duration of progeny in Sclerodermus pupariae (Hymenoptera: Bethylidae). — Biol. Contr. 97: 57-62.

Ghimire M.N. \& Phillips T.W. 2014: Oviposition and reproductive performance of Habrobracon hebetor (Hymenoptera: Braconidae) on six different pyralid host species. - Ann. Entomol. Soc. Am. 107: 809-817.

GüNDÜZ E.A. \& GüLEL A. 2005: Investigation of fecundity and sex ratio in the parasitoid Bracon hebetor Say (Hymenoptera: Braconidae) in relation to parasitoid age. - Turk. J. Zool. 29: 291-294.

Harvey J.A., Cloutier J., Visser B., Ellers J., Wackers F.L. \& GoLs R. 2012: The effect of different dietary sugars and honey on longevity and fecundity in two hyperparasitoid wasps. - $J$. Insect Physiol. 58: 816-823.

Huang Y.Z., Dai A.Q., Liu Y.Y., Jiang X.C. \& TAng Q.F. 2018: Effects of mating condition of parent wasp on mating behavior and offspring sex allocation for Habrobracon hebetor Say (Hymenoptera: Braconidae). - J. Huazhong Agric. Univ. 37: 52-57.

Hudak K., Lenteren J.C., Qiu Y.T. \& Penzes B. 2003: Foraging behaviour of parasitoids of Bemisia argentifolii on poinsettia. — Bull. Insectol. 56: 259-267.

JARRAHI A. \& SAFAVI S.A. 2016: Sublethal effects of Metarhizium anisopliae on life table parameters of Habrobracon hebetor parasitizing Helicoverpa armigera larvae at different time intervals. - J. Int. Organiz. Biol. Contr. 61: 167-175.

Kabore A., Ba N.M., Dabire-Binso C. \& SAnon A. 2019: Towards development of a parasitoid cottage industry of the parasitoid wasp Habrobracon hebetor (Say): Optimum rearing and releases conditions for successful biological control of the millet head miner Heliocheilus albipunctella (De Joannis) in the Sahel. - Int. J. Trop. Insect Sci. 39: 25-33.

Kryukov V.Y., Kryukovana A. \& GLupov V.V. 2013: Susceptibility of Galleria mellonella larvae to anamorphic entomopathogenic ascomycetes under envenomation and parasitization by Habrobracon hebetor. - Russ. J. Ecol. 44: 89-92.

MAgro S.R. \& PARRA J.R.P. 2001: Biology of the ectoparasitoid Bracon hebetor (Hymenoptera: Braconidae) on seven lepidopteran species. - J. Agric. Sci. 58: 693-698.

Majeed A.S., Abdoolnabi B., Mohsen B., Dousti A.F. \& PARICHehreh S. 2018: Mating and carbohydrate feeding im- 
pacts on life-history traits of Habrobracon hebetor (Hymenoptera: Braconidae). - J. Econ. Entomol. 111: 2605-2610.

Mbata G.N., Eason J., Payton M.E. \& Davis M.F. 2017: Putative host volatiles used by Habrobracon hebetor (Hymenoptera: Braconidae) to locate larvae of Plodia interpunctella (Lepidoptera: Pyralidae). - J. Insect Behav. 30: 287-299.

Michaud J.P. 2018: Problems inherent to augmentation of natural enemies in open agriculture. - Neotrop. Entomol. 47: 161170.

Mironidis G.K. \& Savopoulou-Soultani M. 2009: Development, survival and growth rate of the Hyposoter didymator-Helicoverpa armigera parasitoid-host system: effect of host instar at parasitism. - Biol. Contr. 49: 58-67.

NAY J.E. \& PERRING T.M. 2005: Impact of ant predation and heat on carob moth (Lepidoptera: Pyralidae) mortality in California date gardens. - J. Econ. Entomol. 98: 725-731.

Nikam P.K. \& Pawar C.V. 1993: Life tables and intrinsic rate of natural increase of Bracon hebetor Say (Hym., Braconidae) population on Corcyra cephalonica Staint. (Lep., Pyralidae), a key parasitoid of Helicoverpa armigera Hbn. (Lep., Noctuidae). - J. Appl. Entomol. 115: 210-213.

Saxena H., Ponnusamy D. \& Iquebal M.A. 2012: Seasonal parasitism and biological characteristics of Habrobracon hebetor (Hymenoptera: Braconidae) - a potential larval ectoparasitoid of Helicoverpa armigera (Lepidoptera: Noctuidae) in a chickpea ecosystem. - Biocontr. Sci. Technol. 2: 305-318.

Sivinski J., Aluja M. \& Holler T. 2006: Food sources for adult Diachasmimorpha longicaudata, a parasitoid of tephritid fruit flies: effects on longevity and fecundity. - Entomol. Exp. Appl. 118: 193-202.

Tang Q.Y. \& Feng M.G. 2002: DPS Data Processing System for Practical Statistics. Science Press, Beijing, 648 pp. [in Chinese].

Teraoka T. \& Numata H. 2000: Effects of feeding on reproduction and overwintering in female adults of Ooencyrtus nezarae Ishii (Hymenoptera: Encyrtidae). - App. Entomol. Zool. 35: 361-367.

Vaello T., Sarde S.J., Marcos-García M.Á., de Boer J.G. \& PINEDA A. 2018: Modulation of plant-mediated interactions between herbivores of different feeding guilds: Effects of parasitism and belowground interactions. - Sci. Rep. 8: 14424, 8 pp.

YANG L., Chen E.H. \& HuAng X.C. 2006: Feasibility of ecological management of sugarcane pest. - J. Northw. Sci-Tech. Univ. Agric. For. (Nat. Sci.) 2: 57-59.

ZHANG L.S. \& CHEN H.Y. 2014: Advances in research and application of biological control agents in China. - Chin. J. Biol. Contr. 5: 581-586.

Received April 14, 2020; revised and accepted July 28, 2020 Published online October 12,2020 